\title{
Using of Microsilica for Strength Improvement of Fiber Reinforced Cementitious Surface Compounds
}

\author{
S. S. Shebl, Ibrahim S. Khalil, and H. Shoukry \\ Building Physics Institute, Housing \& Building National Research Center, P.O. Box 1770, Cairo, Egypt \\ Correspondence should be addressed to S. S. Shebl; ssshebl@yahoo.com
}

Received 9 September 2012; Accepted 11 October 2012

Academic Editors: K. Hokamoto and V. Ralchenko

Copyright (c) 2013 S. S. Shebl et al. This is an open access article distributed under the Creative Commons Attribution License, which permits unrestricted use, distribution, and reproduction in any medium, provided the original work is properly cited.

\begin{abstract}
This study represents an extension work to investigate the role of ultra fine sand (UFS) in enhancing the mechanical properties of fiber reinforced cementitious compounds. The micro-structural origins were identified by scanning electron microscope (SEM). About $50 \%$ of UFS had a diameter of less than $20 \mu \mathrm{m}$. Ordinary Portland Cement (OPC) was partially substituted by UFS at $3,5,7$ and $10 \%$ by weight of binder. It was found that as UFS loadings increase, the flexural, compressive, and tensile strengths increased up to about 5\% UFS loading by 12.9, 15.7 and 30.1\%, respectively, thereafter, a decrease in these properties was observed. This can be attributed to the pozzolanic effect besides the filling effect of UFS resulting in enhancing the interfacial bonds between the sand grains and hydration products that makes the paste more homogeneous and dense. The effect of both short natural and artificial fiber loadings on the structural performance of compounds was also studied. Loadings of $2 \%$, by weight, of short natural date palm leaves' midribs fibers (DP) and artificial polypropylene fibers (PP) were added to the 5\% UFS blended mix. An increase in both flexural and tensile strength was achieved, while a decrease in the compressive strength was observed.
\end{abstract}

\section{Introduction}

The ultra fine sand (UFS) modifier is microscale crystalline silica which is an industrial waste available in Egypt [1]. This study represents the extension for the previous work that aimed to investigate the role of UFS in enhancing the mechanical and physical properties of cementitious pastes. Generally, the addition of very fine pozzolanic materials to cement paste leads to the formation of very fine hydration products, which in turn lead to a refinement of pores. Sand acts as filler, providing for an economical mix and controlling shrinkage. Either natural sand or processed sand may be used as filler. Gradation limits are given in ASTM C 144 [2]. Gradation can be easily and inexpensively altered by adding fine or coarse sands.

Micro- or nanopozzolanic particles are incorporated as active substitutions to Ordinary Portland Cement (OPC) due to their reactivity with lime forming cementitious compounds with improved mechanical properties [3-7]. As they dispersed in OPC, they generate a large number of nucleation sites for the precipitation of the hydration products resulting in better distribution of fine pores which produces homogeneous and dense microstructure. In addition, denser packing within the cement results from the very fine grains, which reduces the wall effect in the transition zone between the paste and aggregate. This weaker zone is strengthened due to the higher bond developed between these two phases, improving the microstructure and mechanical properties of the blended cement paste. In general, the pozzolanic effect depends not only on the pozzolanic reaction, but also on the physical or filler effect of the smaller particles in the mixture.

Building energy performance depends on the thermal characteristics and particularly on the thermal resistance of the building envelope. Cementitious materials are the most frequently used construction material in the world and even a small improvement in their thermal resistivity can lead to considerable energy savings. In actuality, thermal resistance of cementitious mortar or surface compounds decreases with decreasing cement content and thermal resistivity of aggregates [4]. The use of lightweight cementitious surface compounds with high thermal resistivity, in building envelopes, reduces energy consumption and/or enhances the indoor comfort. The incorporation of lightweight particulate insulation in cementitious material produces lightweight 
compounds with poor mechanical properties and toughness [8]. The basic reasons for the poor mechanical performance of these materials are the weak interfacial adhesion between the cement binder and these insulating particulates as well as the inherit voids and discontinuities in the mix. Therefore, microor nanopozzolanic particles were incorporated as active substitutions of OPC to compensate the mechanical strength degradation by improving toughness and mechanical properties reducing the size and amount of defects in cementitious material leading to better performance. Varieties of fibrous materials had been used for improving toughness and tensile strength performance of cementitious surface compounds and concrete [8-13]. Such materials combined good thermal resistance with enough mechanical strength and very low manufacturing costs. An effective way to improve the toughness of cementitious surface compounds is by adding a small fraction of short fibers to the mix as reinforcement. Short fibers can bridge the cracks in the matrix and provide resistance to crack propagation before being pulled out or stressed to rupture. The effect of short polypropylene fibers loading as artificial fibers source on the indirect tensile strength and fracture resistance of nanostructured perlite cementitious surface compounds had been studied [8]. An increase of $34 \%$ in the indirect tensile strength was achieved at PP fiber loading of $2 \%$. No cracking was observed for 6 months. Also, the interfacial bond between fibers and cementitious composites and its effect on crack resistance and durability was studied. Densification within the fiber bundle and at the fiber/cement interface, caused by the precipitation and growth of cement hydration products, particularly calcium hydroxide $\left(\mathrm{Ca}(\mathrm{OH})_{2}\right)$ crystals appears to be the main reason for the strong interfacial bonds [10]. Dense interface can reduce the curvature through which a fiber bridges a crack, inducing higher stresses and thus an increased chance of failure. In general, incorporating fibers into plain mortar caused a reduction in compressive strength, although it was lesser when steel fibers were added. However, the addition of functionalized micro- or nanosilica-source particles or a highly active pozzolan or slag can help to compensate for this loss of strength. The use of natural fibers as reinforcement to cementitious compounds and concrete was also studied as a way to recycle these natural fibers. The advantages of the natural source of fibers are renewable, nonabrasive, cheaper, abundant and show less concern with health and safety during handling and processing [11-13].

In this paper, microstructured modified fiber reinforced cement mortars are studied and proposed as an alternative for conventional materials. The structural strength behavior of the new materials will be investigated. Potentials on the application of natural and artificial fiber sources for strength improvement of fiber reinforced cementitious surface compounds will be tried.

\section{Materials}

OPC used in the current work was commercially available as CEM I: $42.5 \mathrm{~N}$ manufactured by El Suez Cement Company (El-Suez plant), with Blaine surface area $335 \mathrm{~m}^{2} / \mathrm{kg}$, and

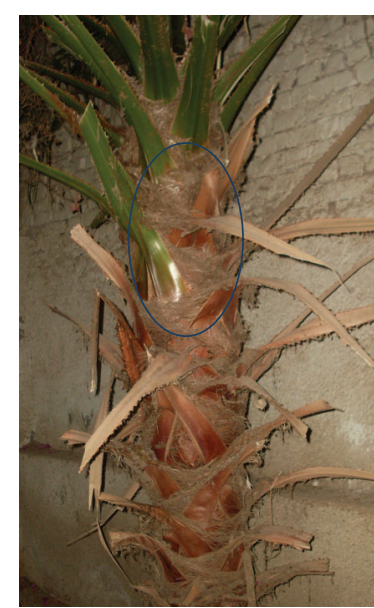

(a)

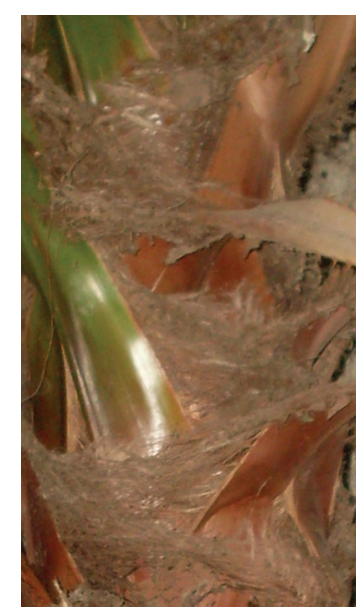

(b)
Figure 1: Photos showing (a) date palm tree; (b) details of date palm leaves' midribs natural fibers.

conforming to the Egyptian Standard Specification ES 4756$1 / 2007$ [14]. The sand used as coarse aggregate was natural siliceous sand with grain size ranging from 0.06 to $5 \mathrm{~mm}$ as adopted by sieve analysis. While, the UFS microscale silica modifier was used as fine aggregate, which was an industrial waste [1]. Particle-size analysis for UFS was performed using a laser beam diffraction technique (LBD). It was found by LBD analysis that about $50 \%$ of UFS had a diameter of less than $20 \mu \mathrm{m}$, while all the UFS had a diameter less than $100 \mu \mathrm{m}$. The chemical compositions of the starting materials (OPC and UFS) evaluated by X-ray fluorescence (XRF) analysis are summarized in Table 1 . Date palm leaves' midribs fibers (DP) had been used representing a natural source of fibers (as shown in Figure 1), while polypropylene fibers (PP) had been used to represent an artificial source (as shown in Figure 2). Short fibers of $20 \mathrm{~mm}$ length, both natural and artificial had been used to produce the fiber reinforced microsilica cement mortars.

\section{Compound Preparation and Identification}

The OPC was partially substituted by the UFS at 3, 5, 7, and $10 \%$ by weight of OPC according to the mix design as illustrated in Table 2. The dry OPC and UFS were shear mixed at a speed of $350 \mathrm{rpm}$ for $2 \mathrm{~min}$ to insure good homogeneity using high power ball miller type PM100 as shown in Figure 3. The blended compounds were prepared by slow mixing for $3 \mathrm{~min}$ using the standard water of consistency as shown in Figure 4. The compounds were molded in stainless steel molds with dimension of $40 \times 40 \times 160 \mathrm{~mm}$ for compression and flexural strengths tests as three samples for each mix. Another set of stainless steel circular molds with diameter of $50 \mathrm{~mm}$ and thickness of $100 \mathrm{~mm}$ were used for indirect tensile strength tests. The samples were kept in molds for $24 \mathrm{~h}$, and then unmolded and allowed to cure in water for 7 days. An optimum percentage of $2 \%$ short fibers addition as recommended by Aglan et al. [8] was used 


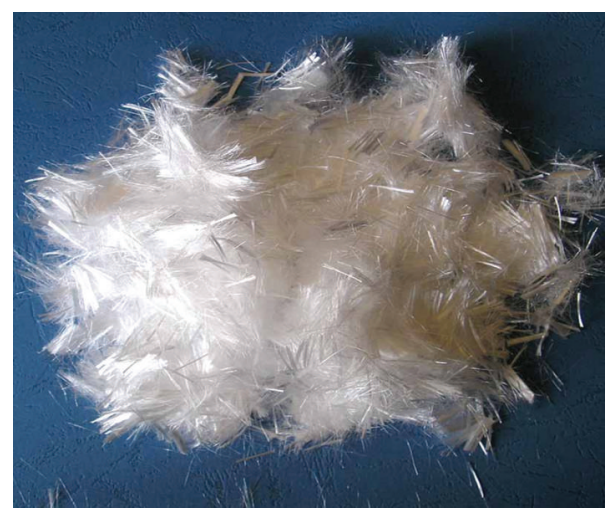

FIGURE 2: Photo of polypropylene artificial fibers.

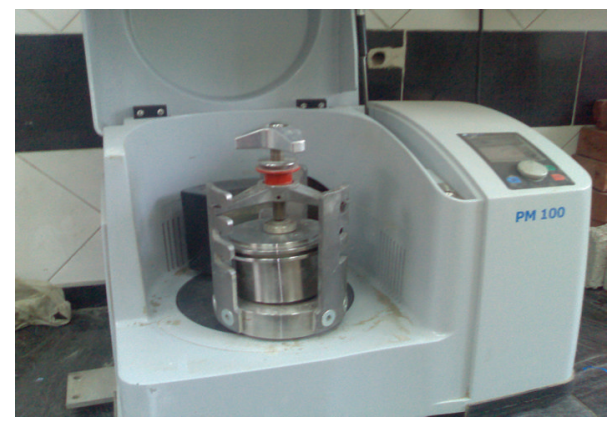

FIgURe 3: Ball miller type PM100.

to get the fiber reinforced cementitious surface compounds after obtaining the optimum percentage of UFS that used as cement replacement. In order to get the short fibers, both the natural DP and artificial PP were cut to lengths up to $20 \mathrm{~mm}$. The dry OPC and UFS were shear mixed in the same manner with the short fibers with the ratios that illustrated in Table 2. The blended compounds were mixed using the standard water of consistency. The samples were kept in molds for $24 \mathrm{~h}$ and then unmolded and allowed to cure in $100 \%$ relative humidity conditions for 7 days. The specimens were dried at a temperature of $105^{\circ} \mathrm{C}$ for $24 \mathrm{~h}$ in an oven before testing. The mechanical strengths were obtained by performing mechanical tests on dried specimens as per ASTM C109/C109M-11 [15] and ASTM C348-08 [16]. INSPECT-S scanning electron microscope (SEM) was used to examine the microstructure of the different mixes.

\section{Mechanical Strength Measurements}

Mechanical strength tests were performed on a materials testing system, MTS-810 machine as shown in Figure 5. The crosshead speed was $2.54 \mathrm{~mm} / \mathrm{min}$. Three samples per mix were tested and the average values are reported. The specimen geometry is shown in Figure 6. The compressive and flexural strength tests were performed according to ASTM C109/C109M and ASTM C 348 using prism specimens with dimensions of $40 \times 40 \times 160 \mathrm{~mm}$ while indirect tensile

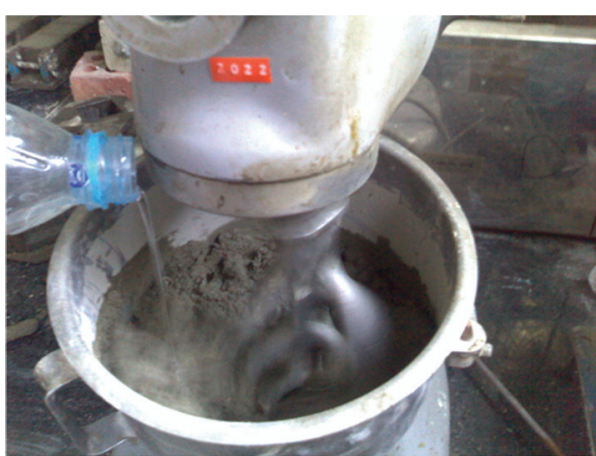

FIgURE 4: Preparing of blended compounds.

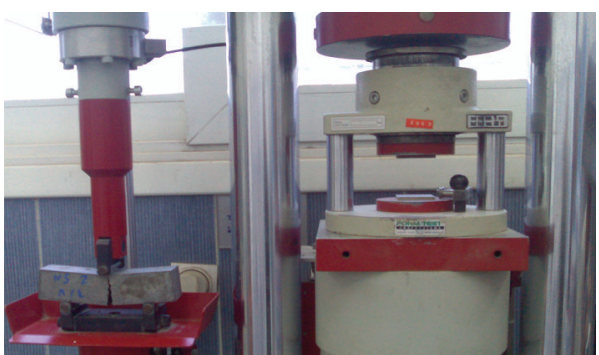

FIGURE 5: Materials testing system, MTS-810 machine.

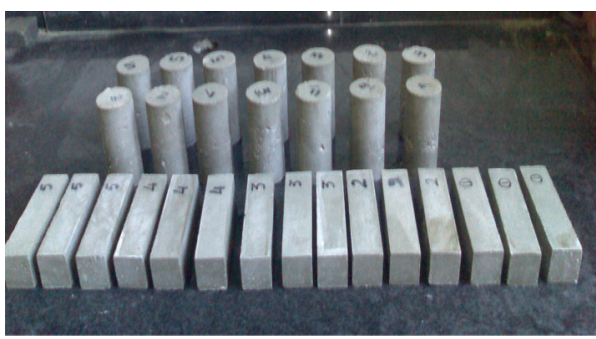

FIGURE 6: Specimens geometry.

tests were performed using cylindrical samples having $50 \mathrm{~mm}$ diameter and $100 \mathrm{~mm}$ thickness.

\section{Results and Discussion}

5.1. Microstructural Analysis. SEM analysis was performed on the typical mixes $0 \%, 5 \%$, and $10 \%$ UFS/cement compounds. The SEM micrographs are shown in Figure 7. The fracture surface of the $0 \% \mathrm{UFS} /$ cement compound is shown in Figure 7(a) and it consists of a combination of smooth and rough areas typical of fracture features of cementitious material. Also, there were some voids, pores and gaps between the cement paste and aggregate which weaken the bond and then reduce the mechanical tensile strength. Figure $7(b)$ shows quite denser microstructure with lesser voids and more compact than the control mix. This indicates that the addition of the 5\% UFS to the cement compound has considerably modified the interfacial transition zone in the mix and increased the bond between the cement paste and aggregate due to the filling effect and the pozzolanic effect of UFS which 


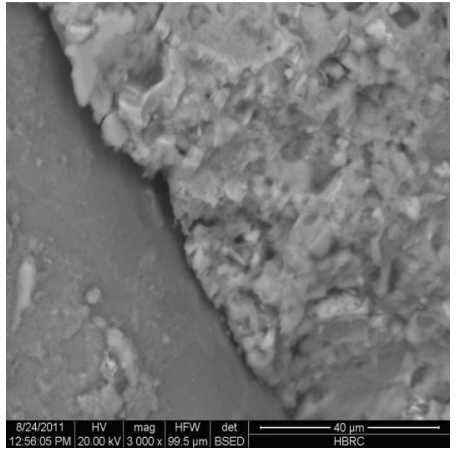

(a)

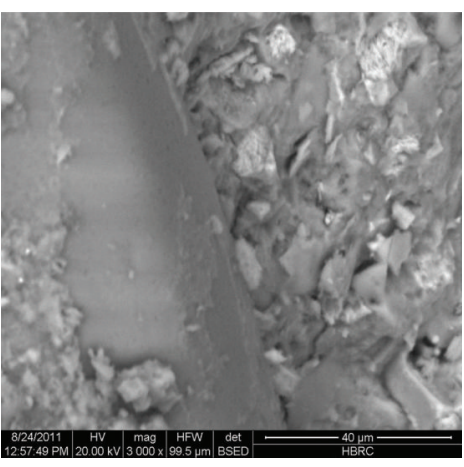

(b)

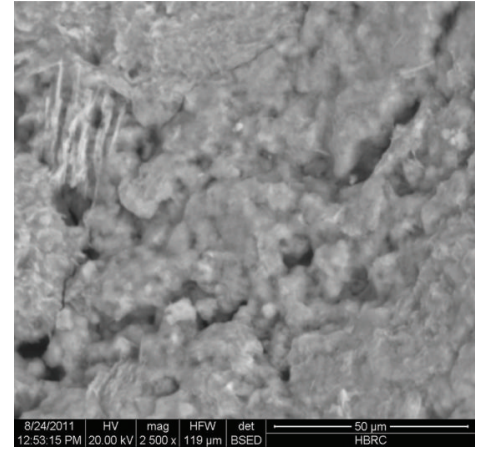

(c)

FIGURE 7: Fracture surface morphology of the 7-day-age (a) 0\%; (b) 5\%; (c) 10\% UFS/cement compound specimens.

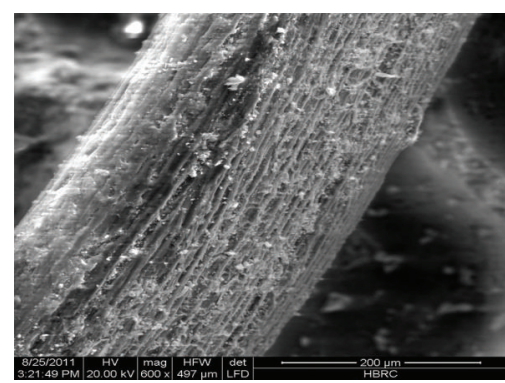

(a)

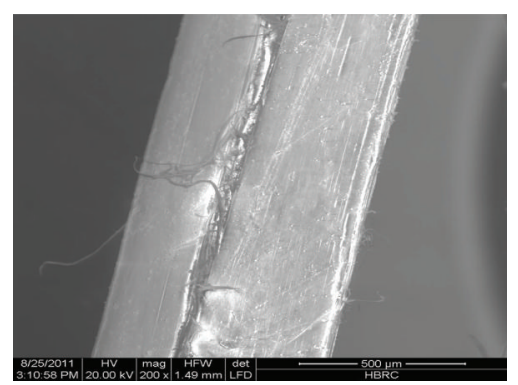

(b)

FIGURE 8: Surface roughness of (a) natural PD and (b) artificial PP fibers.

TABLE 1: Chemical composition of starting materials.

\begin{tabular}{lcccccccc}
\hline $\begin{array}{l}\text { Oxide } \\
\text { composition (\%) }\end{array}$ & $\mathrm{SiO}_{2}$ & $\mathrm{Al}_{2} \mathrm{O}_{3}$ & $\mathrm{Fe}_{2} \mathrm{O}_{3}$ & $\mathrm{CaO}$ & $\mathrm{MgO}$ & $\mathrm{Na}_{2} \mathrm{O}_{2} \mathrm{~K}_{2} \mathrm{SO}_{3}$ \\
\hline OPC & 21.3 & 2.6 & 2.8 & 65.6 & 1.56 & 0.22 & 0.86 & 3.15 \\
UFS & 98.81 & 0.14 & 0.05 & 0.51 & 0.02 & 0.04 & 0.03 & 0.03 \\
\hline
\end{tabular}

improves the microstructure and enhances the mechanical strength. Also, the dispersion of the UFS in the matrix has also improved the hydration process by providing numerous hydration sites for the chemical reaction that makes the paste more homogeneous and dense. As shown in Figure 7(c), with a loading of $10 \%$ UFS, a texture had poor hydration products with excess pores and water pockets created and an increase in the number and the size of voids is observed. Evidently, the increase of UFS replacement increases the mixed water which leads to the formation of more porosity and a reduction in strength after reaching the optimum conditions.

These micrographs can give visual evidence of the microstructural features responsible for the enhancement of the mechanical properties of the UFS modified cement mortar. About 5\% ultra fine particulates as optimum replacement provides the most efficient hydration conditions, then an improvement in the measured strength of the cement compound had been induced.

Also, the SEM micrographs of the surface topography of both artificial PD and natural PP fibers are shown in
TABLE 2: Dry mix composition of blended compounds (wt\%).

\begin{tabular}{lcccccc}
\hline Mixes & OPC & UFS & Sand & Water & DP & PP \\
\hline S0 & 100 & 0 & 275 & 48.5 & - & - \\
S1 & 97 & 3 & 275 & 48.5 & - & - \\
S2 & 95 & 5 & 275 & 48.5 & - & - \\
S3 & 93 & 7 & 275 & 48.5 & - & - \\
S4 & 90 & 10 & 275 & 48.5 & - & - \\
S5 & 95 & 5 & 275 & 48.5 & 2 & - \\
S6 & 95 & 5 & 275 & 48.5 & - & 2 \\
\hline
\end{tabular}

Figure 8. As clear from SEM photos, the surface of PP fiber is very soft and smooth; however, the surface of PD fiber is very rough with large wrinkles. This gives the natural fiber a great advantage when used as reinforcement through cement matrix where the wrinkles increase the bond between fiber and matrix than the PP fiber as shown in Figure 9. Increases of toughness over UFS/cement fiber reinforced compounds were commonly observed. Fiber bridging caused crack arrests resulting in a low stress intensity factor at the crack tip. A relatively fiber sliding of the PP fibers compared to PD fibers had weakened the interfacial bonding of the compound as observed in Figure 10, which slightly lowering the toughening mechanism of the PP fiber reinforced UFS cementitious surface compounds. Fiber pullout at the interface has a significant influence on total energy absorption during crack propagation. Thus, the fiber-matrix 

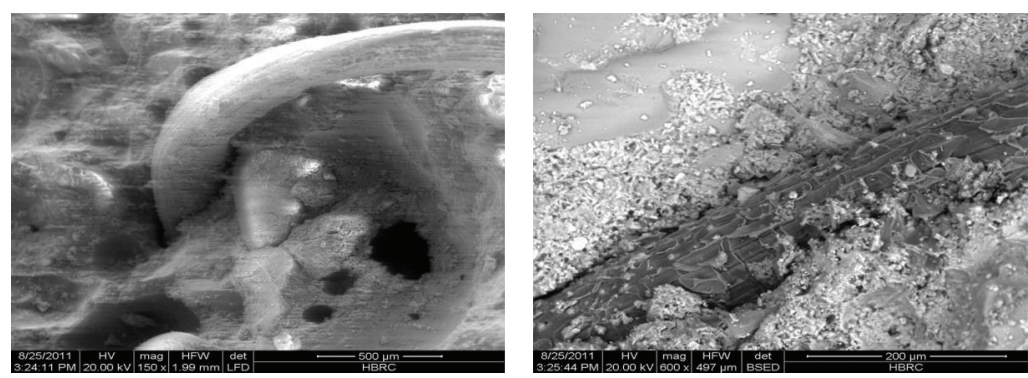

FIGURE 9: Fracture surface morphology of the 7-day-age 5\% UFS/cement with 2\% natural PD reinforced compound specimen.
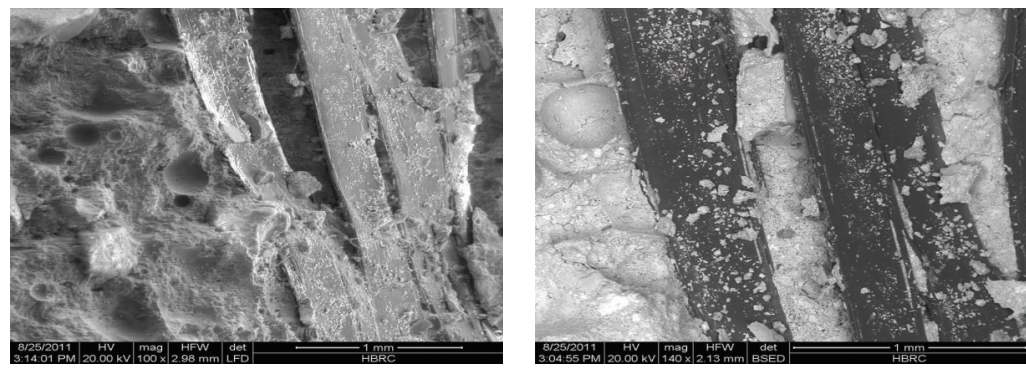

FIGURE 10: Fracture surface morphology of the 7-day-age 5\% UFS/cement with 2\% artificial PP reinforced compound specimen.

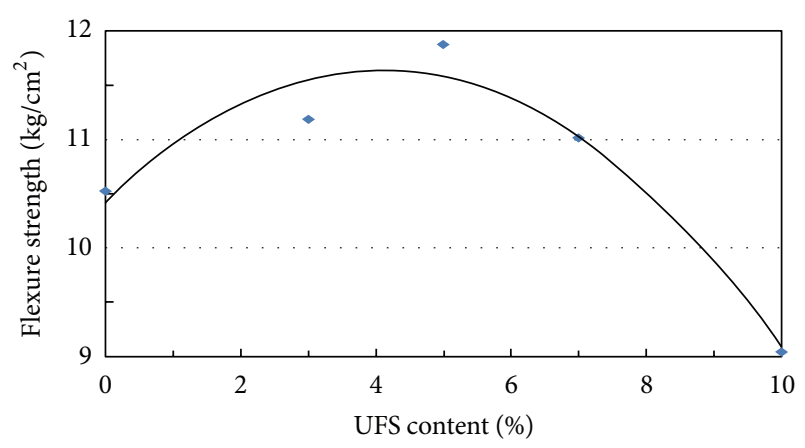

FIGURE 11: Variation of flexure strength of 7-day-age UFS/cement compound with UFS loading.

bond strongly affects the ability of fibers to stabilize crack propagation in the matrix.

5.2. Mechanical Strength. The flexural, compressive, and tensile strength of modified cementitious surface compounds as a function of UFS loading is shown in Figures 11, 12, and 13. It is evident that the flexural, compressive, and tensile strength of the control cement paste increases with UFS loading and a maximum value was reached at about $5 \%$. This represents an increase of nearly about 12.9, 15.7, and $30.1 \%$, respectively. The reasons for early strength increase of modified cement paste up to 5\% cement replacement of UFS may be due to its high silica content, ultra fineness, and specific surface area. The increase of compressive strength may be due to pozzolanic reaction of UFS with free lime, producing more calcium silicate hydrate $\mathrm{CSH}$, which deposits in the pore system making the paste more homogeneous

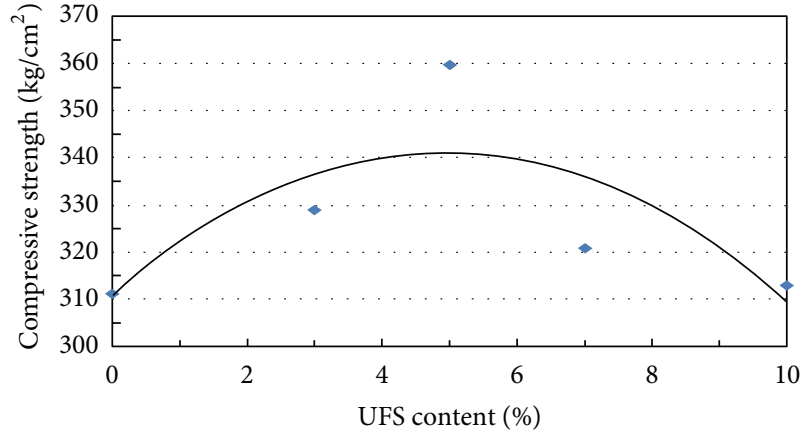

FIGURE 12: Variation of compression strength of 7-day-age UFS/cement compound with UFS loading.

and denser than the control paste. There is also a physical filling effect of the UFS particles acting as bridges across pores resulting in enhancing the interfacial bonds between the sand grains and hydration products that allow the modified cement paste more homogeneous and denser packing improving the microstructure as shown in SEM images. Thereafter, as the UFS loading increases and reaches about $10 \%$ a noticeable decrease in the strength occurred. Increasing the UFS loading above the optimum value can physically affect the pore system of the modified cement paste leading to less dense packing and increasing the wall effect in the transition zone and this can create weak bonds between the phases of the hydration products. Thus, a formation of an undesired pore network can occur. This may be due to the agglomeration of UFS particles around cement grains which lead to retard cement hydration. Also, it may be due to the defects generated through dispersion of UFS particles that 


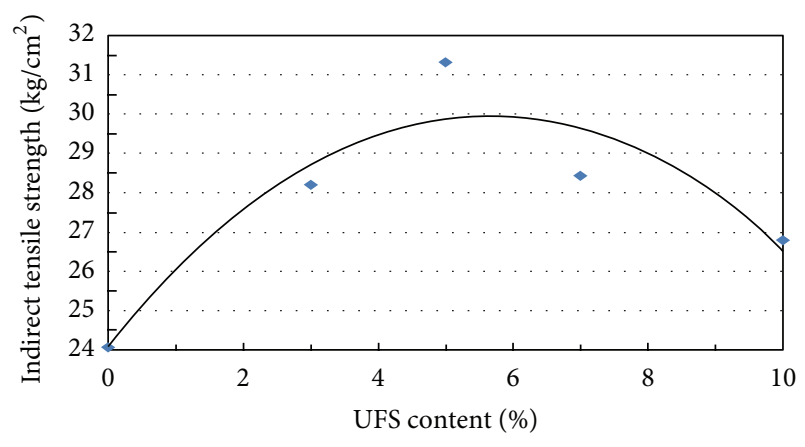

FIGURE 13: Variation of indirect tensile strength of 7-day aged UFS/cement compound with UFS loading.

cause weak zones. Again, excessive porosity will lead to a reduction in the flexural, compressive, and tensile strength of the cement paste. The variation of indirect tensile strength of the modified cement pastes with UFS loadings is shown in Figure 13. A similar trend as those for flexure and compressive strength was noticed. The increasing of tensile strength up to about $5 \%$ cement replacement by USF was about $30.1 \%$ and it is very significant; it can be concluded that it is the optimum UFS percentage loading for modification of the cement compound. The increase of tensile strength may be due to its effect in acting as filler in the interstitial spaces inside the skeleton and enhancing the interaction interfacial bonding between the coarse aggregate grains and hydration products. Further increase of UFS loading produces weak cross-links between hydration products which degrades the tensile strength.

After obtaining the optimum percentage of UFS that used as cement replacement which was $5 \%$, an optimum percentage of $2 \%$ short fibers addition as per Aglan et al. [8] was used to prepare and evaluate the fiber reinforced cementitious surface compounds.

The variation of flexural, compressive, and tensile strength of 7-day-age, 5\% USF/cement cement pastes modified with both short natural PD and artificial PP fibers is shown in Figures 14-16. Loadings of 2\%, by weight, of short date palm leaves' midribs fibers (DP) as natural source and polypropylene fibers (PP) as artificial source were added to the $5 \%$ UFS blended mix which is the optimum UFS replacement percentage. Fiber reinforced generally causes toughness increases over UFS/cement fiber reinforced compounds as commonly observed. It can be noticed that the flexural and tensile strength of the 5\% UFS/cement paste specimens reinforced with $2 \%$ fibers generally increases compared with control specimen as shown in Figure 14 and Figure 16, respectively. This represents that an increase of nearly about 2.6 and $0.7 \%$ in the flexural strength and of about 9.6 and $7 \%$ in the indirect tensile strength was achieved at 2\% DP fibers and PP fibers, respectively. This may due to fiber bridging cause crack arrests allowing low stress intensity factor especially at the crack tip resulting in toughness increasing. The surface of PD fiber is very rough with large wrinkles which increase the bond between fiber and surroundings as explanation for the relatively higher values of the flexural and tensile

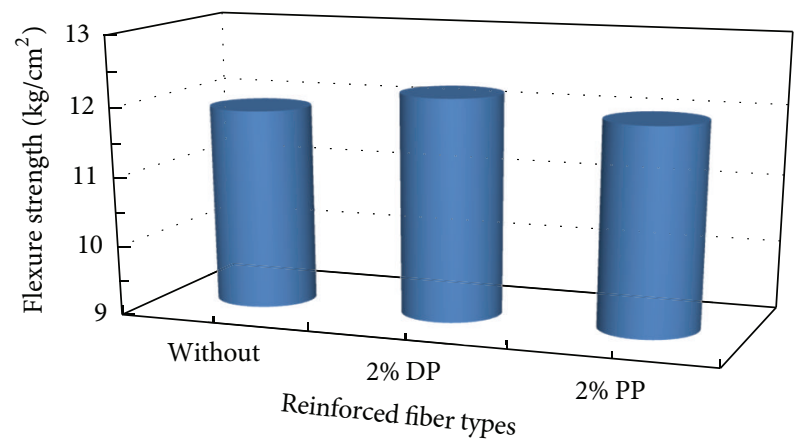

FIGURE 14: Effect of different-types reinforced fiber loading on flexure strength of 7-day-age 5\% UFS/cement compound specimen.

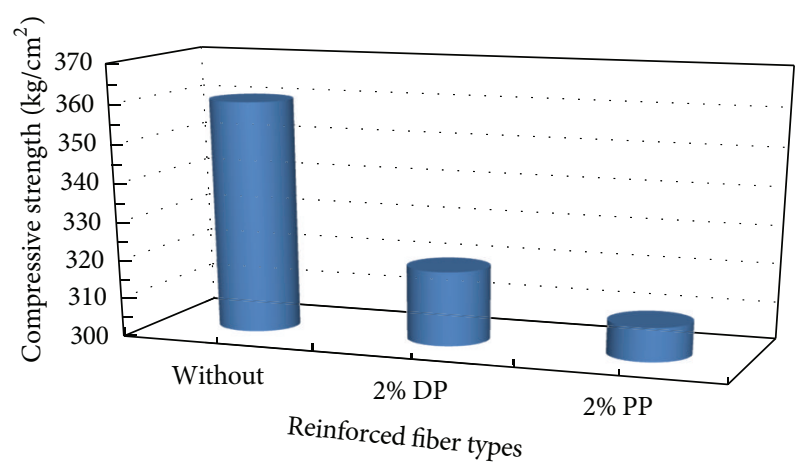

FIGURE 15: Effect of different types of reinforced fiber loading on compressive strength of 7-day-age 5\% UFS/cement compound specimen.

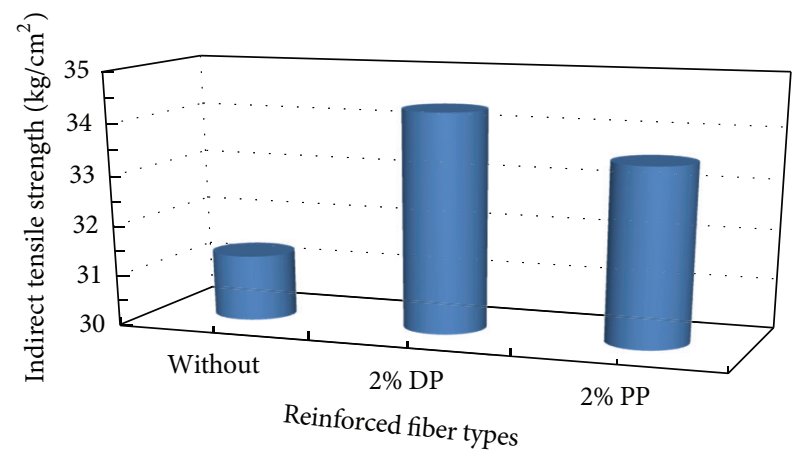

Figure 16: Effect of different types of reinforced fiber loading on indirect tensile strength of 7-day-age 5\% UFS/cement compound specimen.

strength of the PD fiber reinforced UFS cementitious surface compounds. Since, the surface of PP fiber is very soft and smooth allowing relatively fiber pullout at the interface, it weakened the interfacial bonding of the PP-fiber reinforced UFS-cementitious surface compounds.

As an opposed trend, a decrease of about 11.2 and $14.2 \%$ in the compressive strength was achieved at $2 \% \mathrm{DP}$ fibers and PP fibers, respectively, as shown in Figure 15. This may be due to the fibers' dispersing process that physically affects the pores system distribution leads to excess holes and pores forming 
an undesired pore network, thereby leading to less dense packing that causes the compressive strength to decrease.

\section{Conclusions}

The main conclusions that were drawn from the current study can be summarized as follows.

(i) The replacement of cement by the microsilica source UFS can be considered as helpful tool in enhancing the flexure, compression, and tensile strength of cement compounds with an optimum replacement of about $5 \%$ has been reached.

(ii) The UFS physically reacts and appreciably enhances the interfacial bond provides a uniform, denser, and more homogeneous paste.

(iii) Using of $2 \%$ natural DP or artificial PP fibers enhances both the flexural and the indirect tensile strength, while in the opposite direction a decrease in the compressive strength was achieved.

(iv) An increase of the tensile strength of the modified cement paste with about $5 \%$ UFS loading was reached at about $30.1 \%$. Also, an additional increase with about 9.6 and $7 \%$ was achieved of the modified cement paste with about 5\% UFS loading at 2\% DP fibers and PP fibers, respectively.

(v) Modified cement pastes with microsilica and reinforcement by natural or artificial fibers were excellent and their application as building envelope skin is recommended.

\section{Acknowledgments}

This study was extracted from the third report of the National Research Program "Applications of nanomaterials to Improve Mechanical and Thermophysical Properties of Building and Construction Materials." The authors are grateful to Housing and Building National Research Center (HBRC) for providing financial support to thier National Research Program.

\section{References}

[1] S. S. Shebl, H. S. Seddeq, and H. A. Aglan, "Effect of micro-silica loading on the mechanical and acoustic properties of cement pastes," Construction and Building Materials, vol. 25, no. 10, pp. 3903-3908, 2011.

[2] ASTM C144-11, "Standard specifications for aggregate for masonry mortar," 2011.

[3] M. S. Morsy and S. S. Shebl, "Effect of silica fume and metakaoline pozzolana on the performance of blended cement pastes against fire," Ceramics-Silikaty, vol. 51, no. 1, pp. 40-44, 2007.

[4] M. S. Morsy and H. A. Aglan, "Development and characterization of nanostructured-perlite-cementitious surface compounds," Journal of Materials Science, vol. 42, no. 24, pp. 1018810195, 2007.

[5] H. A. Aglan, S. S. Shebl, M. A. Morsy, M. Calhoun, H. Harding, and M. Ahmad, "Strength and toughness improvement of cement binders using expandable thermoplastic microspheres," Construction and Building Materials, vol. 23, no. 8, pp. 28562861, 2009.

[6] S. S. Shebl, L. Allie, M. S. Morsy, and H. A. Aglan, "Mechanical behavior of activated nano silicate filled cement binders," Journal of Materials Science, vol. 44, no. 6, pp. 1600-1606, 2009.

[7] M. S. Morsy, H. A. Aglan, and M. M. Abd El Razek, "Nanostructured zonolite-cementitious surface compounds for thermal insulation," Construction and Building Materials, vol. 23, no. 1, pp. 515-521, 2009.

[8] H. Aglan, M. Morsy, A. Allie, and F. Fouad, "Evaluation of fiber reinforced nanostructured perlite-cementitious surface compounds for building skin applications," Construction and Building Materials, vol. 23, no. 1, pp. 138-145, 2009.

[9] W. Yao, J. Li, and K. Wu, "Mechanical properties of hybrid fiberreinforced concrete at low fiber volume fraction," Cement and Concrete Research, vol. 33, no. 1, pp. 27-30, 2003.

[10] R. M. Gutierrez, L. N. Díaz, and S. Delvasto, "Effect of pozzolans on the performance of fiber reinforced mortars," Cement and Concrete Composties, vol. 27, no. 5, pp. 593-598, 2005.

[11] K. Bilba, M. A. Arsene, and A. Ouensanga, "Sugar cane bagasse fibre reinforced cement composites. Part I. Influence of the botanical components of bagasse on the setting of bagasse/cement composite," Cement and Concrete Composites, vol. 25, no. 1, pp. 91-96, 2003.

[12] J. M. L. Reis, "Fracture and flexural characterization of natural fiber-reinforced polymer concrete," Construction and Building Materials, vol. 20, no. 9, pp. 673-678, 2006.

[13] N. G. Jústiz-Smith, G. J. Virgo, and V. E. Buchanan, "Potential of Jamaican banana, coconut coir and bagasse fibres as composite materials," Materials Characterization, vol. 59, no. 9, pp. 1273$1278,2008$.

[14] Egyptian Standard Specifications, "Composition, specifications and conformity criteria for common cements," Part 1, ES, 47561, 2007.

[15] ASTM C 109/ 109M-11, "Standard test method for compressive strength of hydraulic cement mortars (using 2-in. or [50-mm] cube specimens)," 2011.

[16] ASTM C348-08, "Standard test method for flexural strength of hydraulic-cement mortars," 2008. 

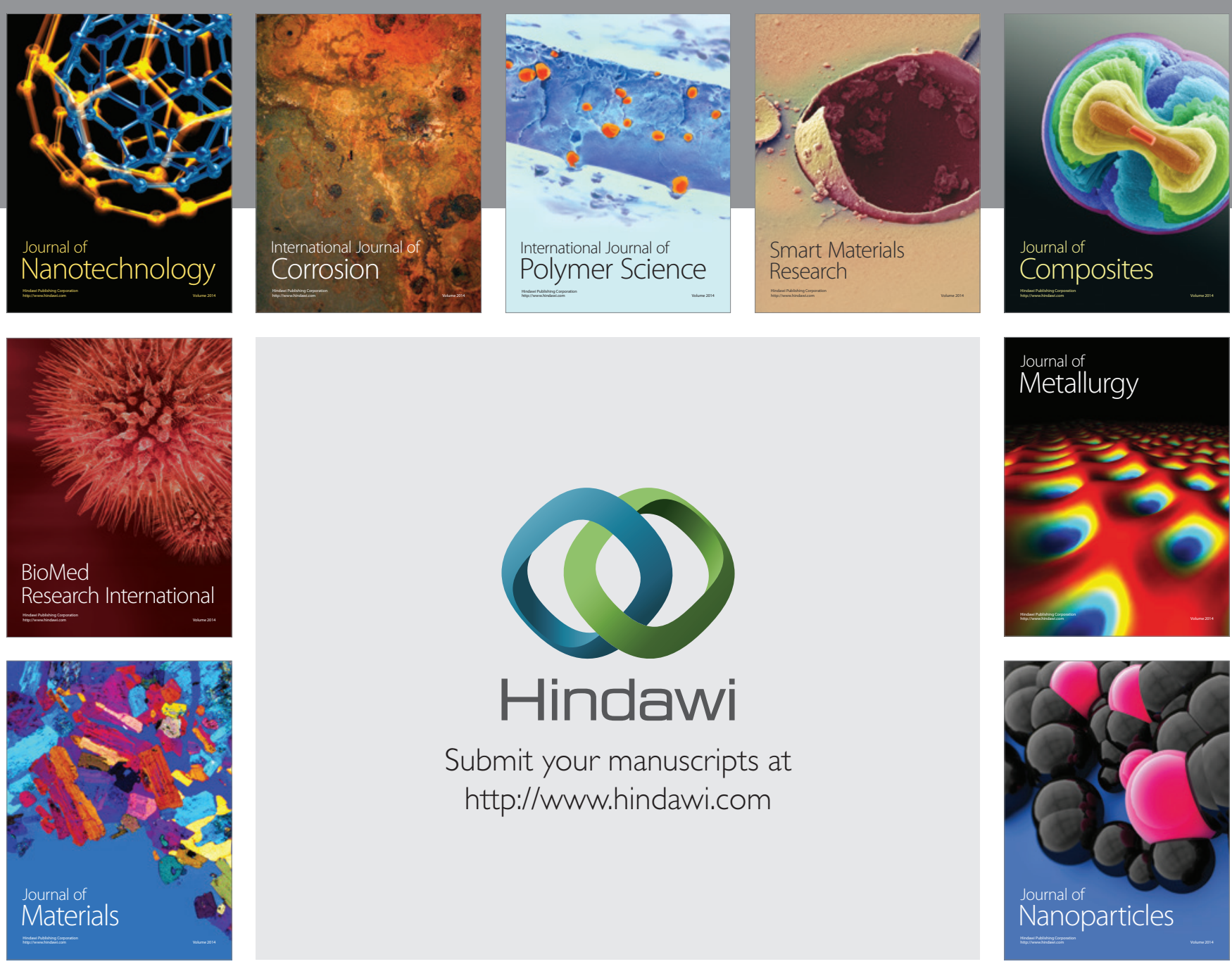

Submit your manuscripts at http://www.hindawi.com
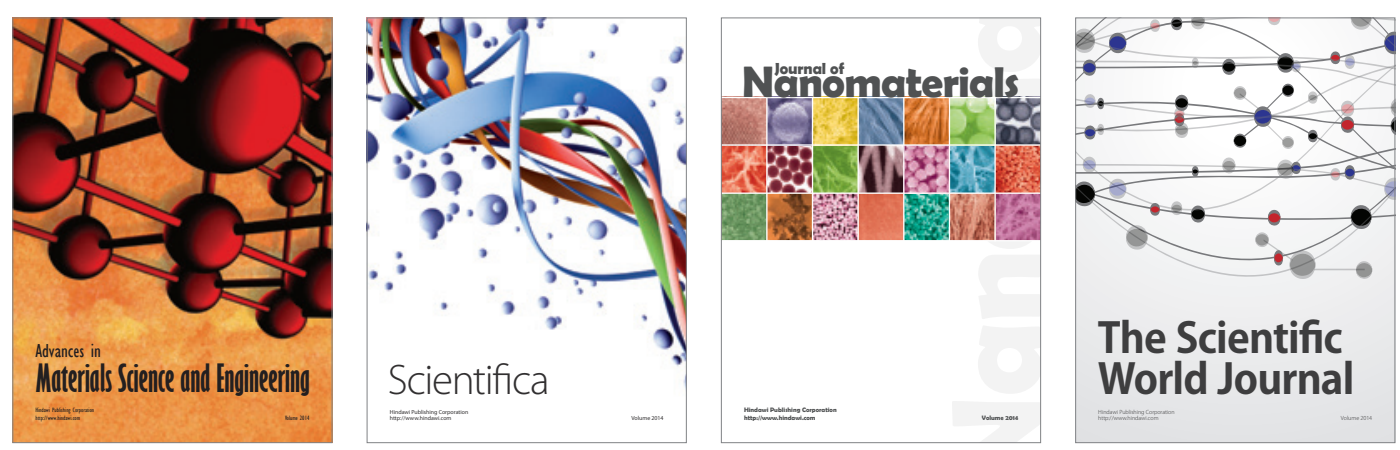

\section{The Scientific World Journal}
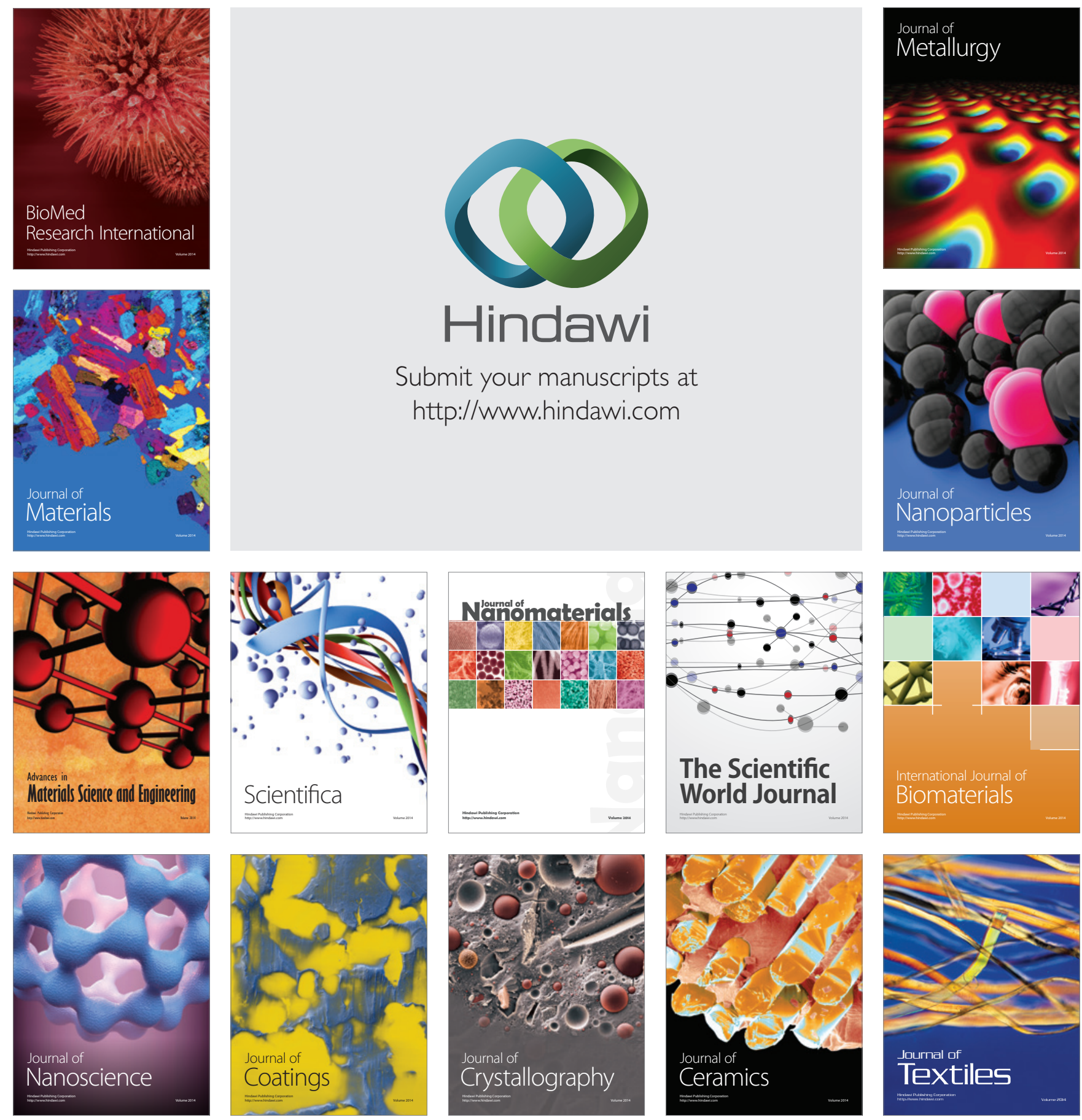